\title{
Experimental and Theoretical Investigation of Subnanosecond Pulse Propagation in Graded Index Fibers
}

\author{
Nicolaisen, Ejner; Hansen, J. J. Ramskov
}

Published in:

Microwave Conference, 1977. 7th European

Link to article, DOI:

10.1109/EUMA.1977.332399

Publication date:

1977

Document Version

Publisher's PDF, also known as Version of record

Link back to DTU Orbit

Citation (APA):

Nicolaisen, E., \& Hansen, J. J. R. (1977). Experimental and Theoretical Investigation of Subnanosecond Pulse Propagation in Graded Index Fibers. In Microwave Conference, 1977. 7th European (pp. 24-28). IEEE. https://doi.org/10.1109/EUMA.1977.332399

\section{General rights}

Copyright and moral rights for the publications made accessible in the public portal are retained by the authors and/or other copyright owners and it is a condition of accessing publications that users recognise and abide by the legal requirements associated with these rights.

- Users may download and print one copy of any publication from the public portal for the purpose of private study or research.

- You may not further distribute the material or use it for any profit-making activity or commercial gain

- You may freely distribute the URL identifying the publication in the public portal 
EXPERIMENTAL AND THEORETICAL INVESTIGATION OF SUBNANOSECOND

PULSE PROPAGATION/IN GRADED INDEX FIBERS

E. Nicolaisen* and J.J. Ramskov Hansen*

ABSTRACT

The propagation in a fibre which does not exhibit any mode coupling is investigated by varying the launching conditions. It is shown that for this fibre there exists a trade-off between dispersion and power coupling efficiency. The measurements are compared to theoretical calculations taking leaky modes and material dispersion into account and good agreement is obtained.

\section{INTRODUCTION}

It is the purpose of this paper to perform a detailed experimental and theoretical analysis of the influence of the launching conditions on the impulse response of a graded index fibre. A theoretical investigation for step index fibres has earlier been made [1].

\section{THEORY}

We are investigating fibres in which many modes can propagate and can therefore use the WKB method to calculate the propagation constant and group delay of each mode.

In a graded index fibre with refractive index $n(r)$ as a function of radius $r$ the propagation constant of each LP $\mu \nu$ mode (linearly polarized) is determined by

$$
\int_{r}^{r} u d r=\left(\mu+\frac{1}{2}\right) \pi
$$

where

$$
u=\sqrt{n^{2}(r) k^{2}-B^{2}-v^{2} / r^{2}}
$$

here $\mu$ and $\nu$ are the number of zeros in radial and azimuthal direction, respectively. The free-space wave number is $k=2 \pi / \lambda$ and $r_{1}$ and $r_{2}$ are the zeros of the integrand. Guided modes are determined by ${ }^{1} \beta \geq \mathrm{n}(\mathrm{a}) \mathrm{k}$ and leaky modes by $\beta<\mathrm{n}(\mathrm{a}) \mathrm{k}$, a is the core radius.

We express the refractive index by

$$
\mathrm{n}^{2}(\mathrm{r})=\mathrm{n}_{1}^{2}(1-2 \Delta \mathrm{f}(\mathrm{r} / \mathrm{a}))
$$

where $f(0)=0$ and $f(1)=1$

We can then calculate the group delay $\tau$ as

* Electromagnetics Institute

Technical University of Denmark

DK-2800 Lyngby, Denmark: 


$$
\tau=\frac{\partial \beta}{\partial \omega}=\frac{1}{c} \frac{\partial \beta}{\partial k}=-\frac{1}{c} \frac{\partial \mu / \partial k}{\partial \mu / \partial \beta}
$$

by using equation ( 1 ) we get

$$
\tau=\frac{\int_{1}^{r_{1}} k\left(\frac{N_{1}}{n_{1}} n^{2}(r)-\lambda \frac{\Delta^{\prime}}{2 \Delta}\left(n^{2}(r)-n_{1}{ }^{2}\right)\right) / u d r}{\int_{r_{1}}^{r} \beta / u d r}
$$

where $\mathrm{N}_{1}=\mathrm{n}_{1}-\lambda \mathrm{n}^{\prime}$ is the group index and a prime denotes differentiation with respect to the wavelength $\lambda$.

If the index profile is a pure $\alpha$-profile i.e. $f(r / a)=(r / a)^{\alpha}$, then $\beta$ and $\tau$ can be calculated analytically [2]. In all other cases they must be numerically calculated.

Equation (5) depends implicitly on the wavelength through $\Delta^{\prime}$. Analytical expressions for the refractive index as a function of wavelength have been determined for several glass compositions [3], [4].

The numerical calculations have been compared with the exact known values in the case of $f(r / a)=(r / a)^{2}$. It is found that $\beta$ is determined with 8 correct digits and $\tau$ with 6 correct digits. It is necessary to have such a high degree of accuracy since we are interested in the difference between the group delays.

\section{EXPERIMENTAL SET-UP}

A diagram of the set-up for the measurement of pulse response is shown in fig. 1.

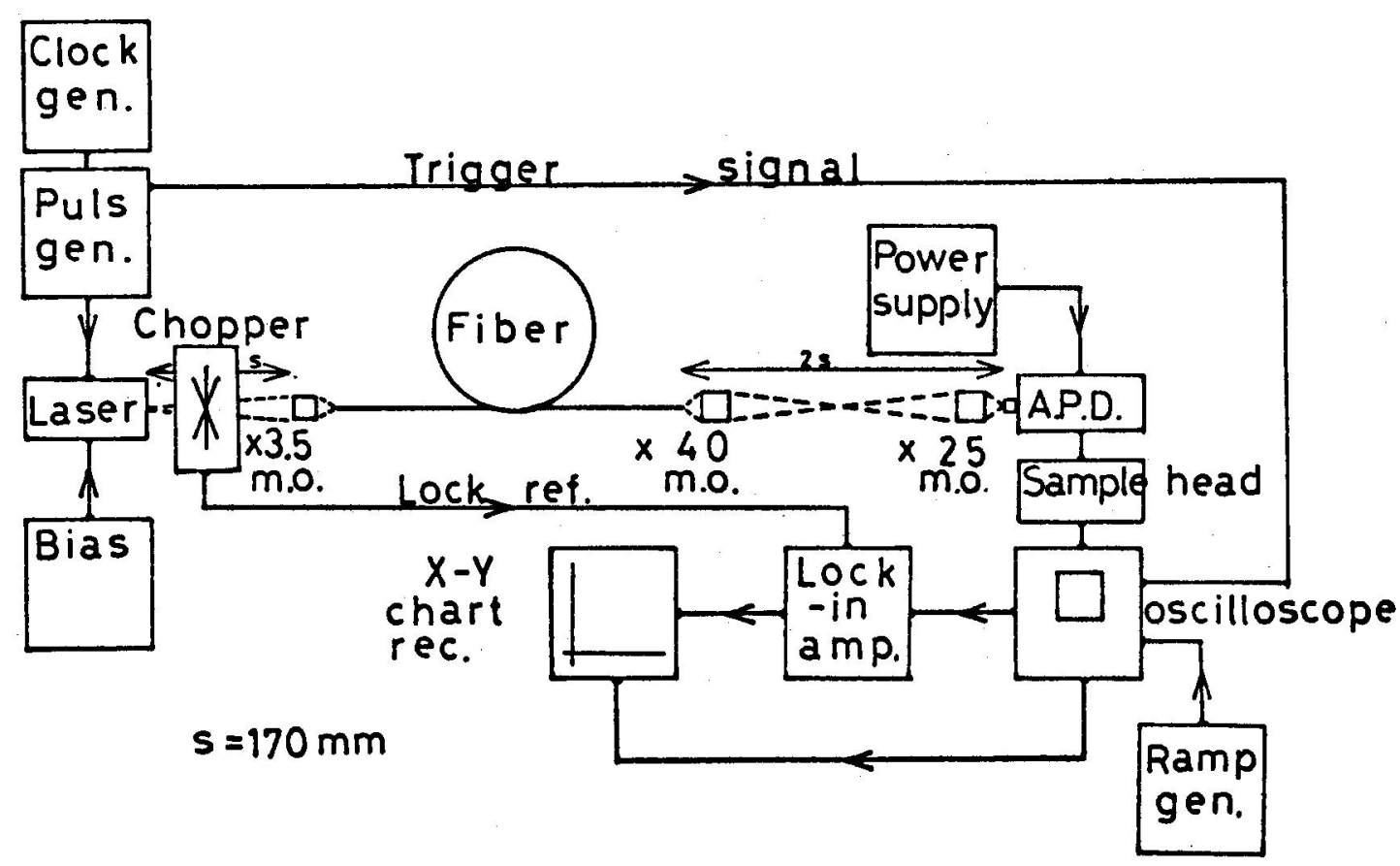

Fig. 1. Experimental set-up 
The laser (RCA) is operating self-pulsing with light pulses of 250 psec (FWHM). The spectral width has been measured to $35 \AA$ (FWHM). The fibre is a $\mathrm{GeO}_{2}$ doped graded index fibre from Schott at the length of $1112 \mathrm{~m}$. The numerical aperture is $\mathrm{N} . \mathrm{A} .=0.25$ and the core radius $\mathrm{a}=21.5 \mu \mathrm{m}$. The index profile has been measured by the near-field method and is shown in fig. 2. In this fibre 100 guided and 31 leaky LP modes can then propagate.
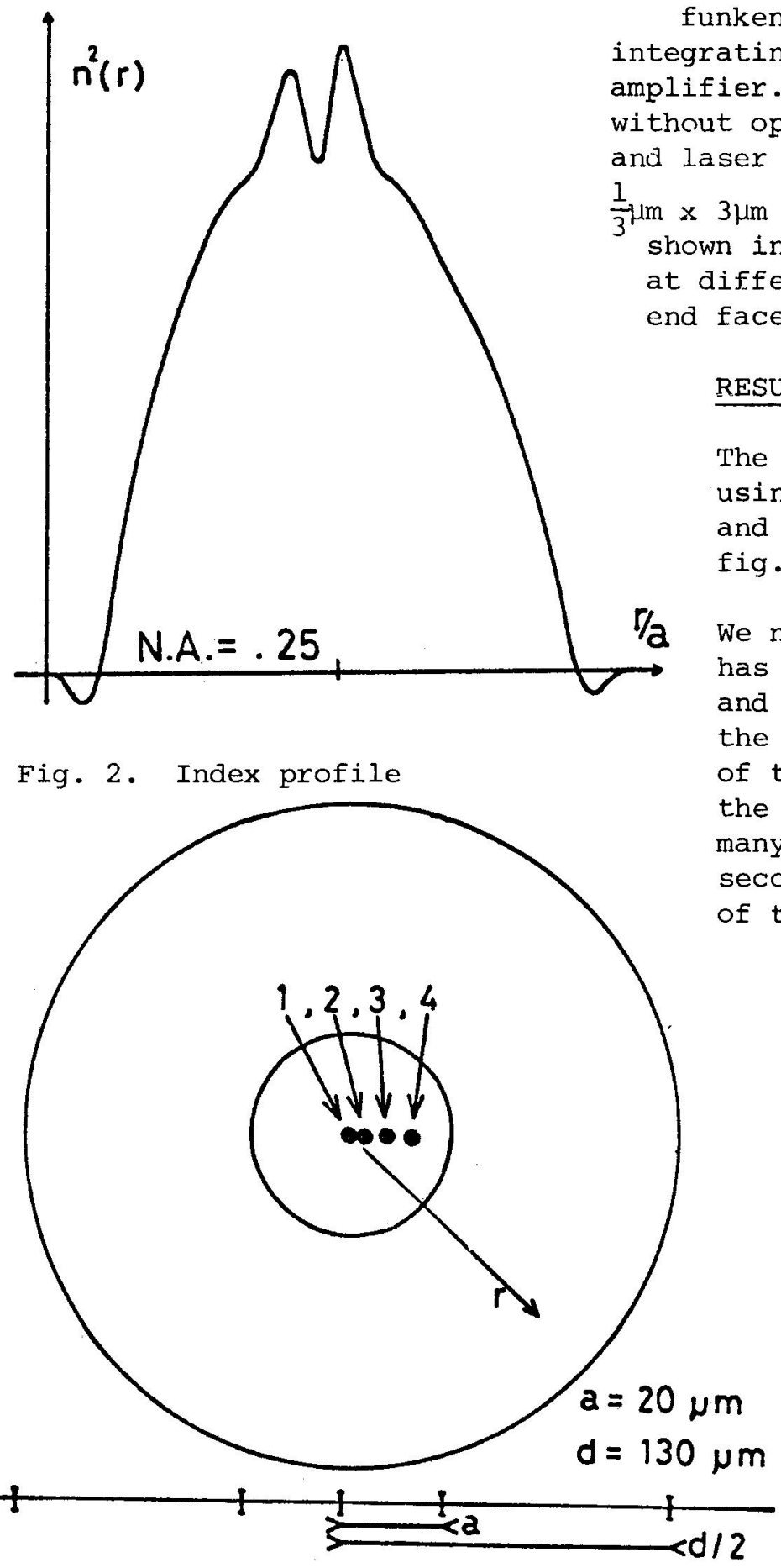

Fig. 3. Spot excitation on the fibre end face
The detector is an APD from Telefunken. A good SNR is obtained by integrating the signal in the lock-inamplifier. The fibre is either excited without optics inserted between fibre and laser or with a small spot of size $\frac{1}{3} \mu \mathrm{m} \times 3 \mu \mathrm{m}$ obtained by the $3.5 \times \mathrm{M} . \mathrm{O}$. as shown in fig. 1. The spot is placed at different positions on the fibre end face as shown in fig. 3.

\section{RESULTS}

The measured pulse responses when using excitation without optics and spot excitation are shown in fig. 4 and fig. 5, respectively.

We note that the pulse response has three peaks and that the second and third peaks are largest when the fibre is excited at the centre of the core. This indicates that the first peak consists of the many higher order modes and the second and third peaks consist of the few lower order modes. It should be noted that it is impossible to obtain such pulse responses if the index profile is a pure $\alpha$-profile. The calculated responses are shown in fig. 6 and fig. 7.

In fig. 6 is shown the pulse response with and without leaky modes taken into account. The leaky modes are modes of high order and all of them arrive in the first peak. Fig. 6 can be compared to fig. 4 since the excitation is nearly equal.

Since it is very difficult to calculate the excitation coefficients for the spot excitation shown in fig. 3 , 


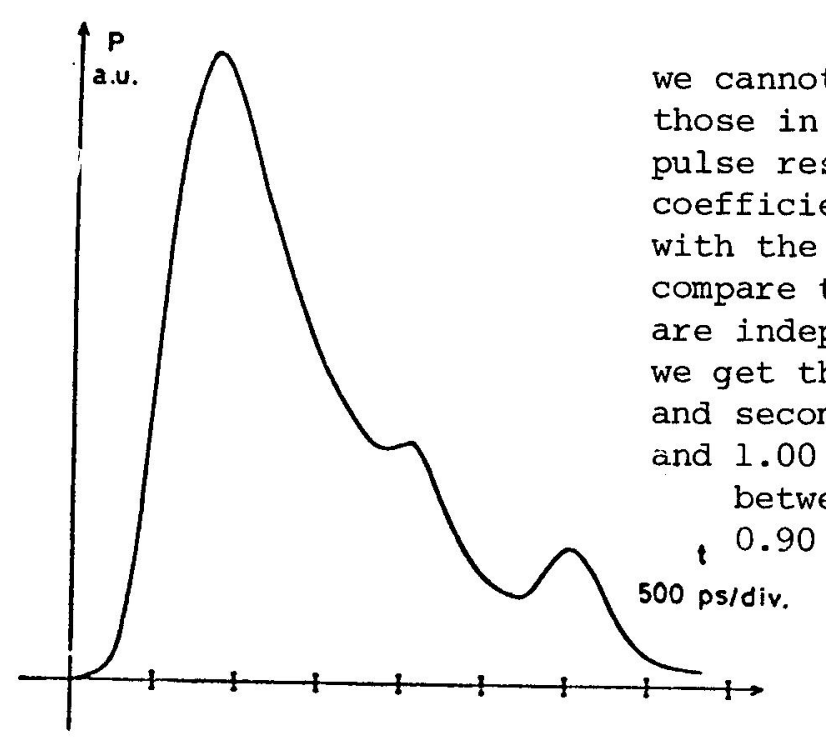

Fig 4. Measured pulse response with excitation without optics.
The main difference between the calculated curves and the measured curves is the fourth peak on the calculated curves. This peak consists only of the LP mode which propagate between 00 $r_{1} / a=0.036$ and $r_{2} / a=0.203$

(eq. (1)). The refractive index within

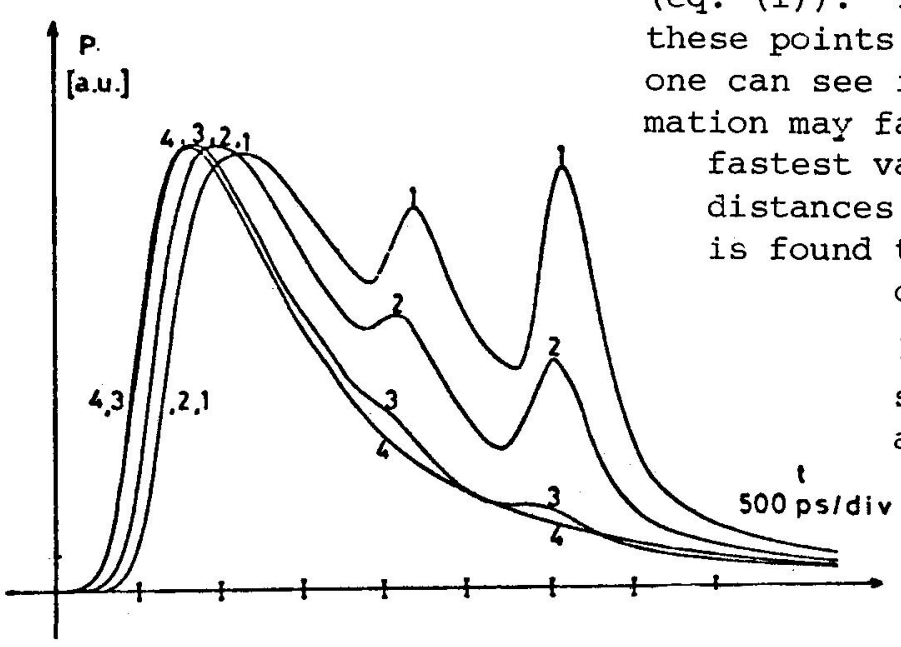

Fig. 5. Measured pulse response with spot excitation as shown in fig. 3 .

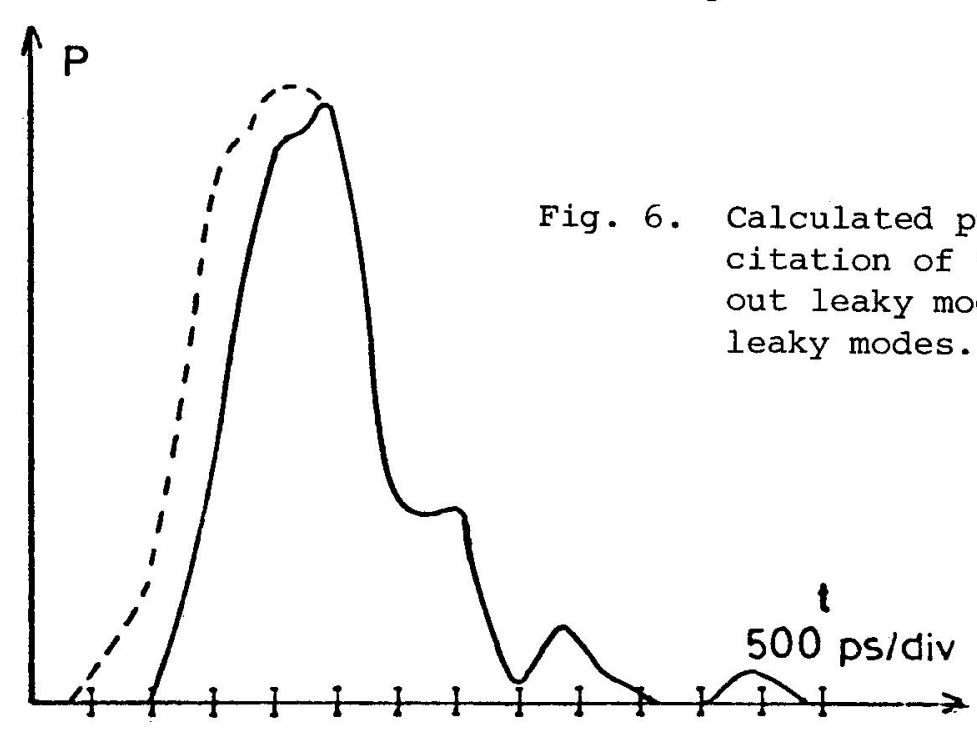




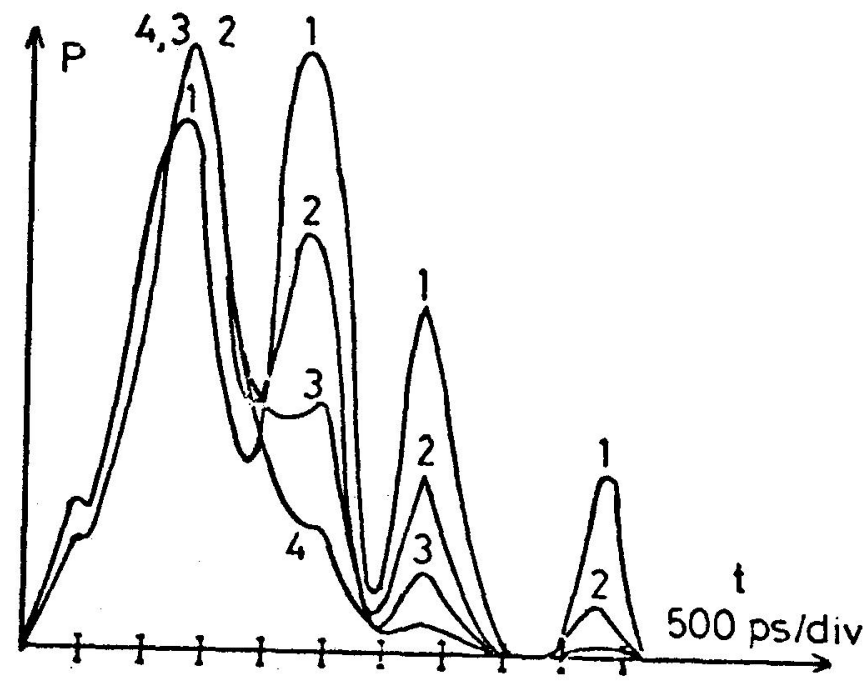

Fig. 7. Calculated pulse response with different excitation.

\section{CONCLUSION}

We have obtained good agreement between theoretical calculations and measurements of the impulse response of a graded index fibre. We have shown that the impulse response highly depends on the launching conditions and a steady-state mode excitation therefore is preferable if one wants a reproducible measuring method.

\section{ACKNOWLEDGEMENT}

This work was supported by the Danish Government Fund for Scientific and Industrial Research.

We wish to thank Dr. M. Leppihalme from the semiconductor Laboratory, Technical Research Centre, Finland, who determined the doping material in the fibre.

\section{REFERENCES}

[1] G. Jacobsen and J.J. Ramskov Hansen, "Transfer function of a multimode step index fiber: A geometrical optical investigation", Opt. and Quant. Electr. vol 9, July 1977.

[2] D. Gloge and E.A.J. Marcatili, "Multimode Theory of Graded-Core Fibers", B.S.T.J. vol. 52, pp 1563-1578, 1973.

[3] I.M. Malitson, "Interspecimen Comparison of the refractive index of fused silica", J.Opt. Soc. A, vol. 55, pp 1205-1209, 1965.

[4] H.M. Presby and I.P. Kaminow, "Binary silica optical fibers: refractive index and profile dispersion measurements", App. Optics, vol 15, pp 3029-3036, 1976. 